\title{
The Effect of Glucocorticoids on Thyrotropin Secretion
}

\author{
JOHN F. WIIBER and Robert D. UTIGER \\ From the Departments of Medicine, Northwestern University School of \\ Medicine, Chicago, Illinois 60611 and Washington University School \\ of Medicine, St. Louis, Missouri 63110
}

A B S T R A C T The effect of large doses of glucocorticoids on thyrotropin (TSH) secretion in normal and hypothyroid humans has been studied. Plasma TSH concentrations were measured before, during, and after treatment with dexamethasone given orally for $24-48 \mathrm{hr}$. In 17 patients with primary hypothyroidism, plasma TSH levels fell significantly during treatment to a mean of $54 \%$ of control (range 23-96\%). Within 48 $\mathrm{hr}$ after the withdrawal of dexamethasone, TSH concentrations transiently increased above pretreatment values. The mean increase was to $156 \%$ of control (range 106294). Similar changes, but of smaller magnitude, were observed in 15 normal subjects. Administration of single oral doses of dexamethasone and oral or intravenous doses of cortisol were followed by reduction of plasma TSH levels to $18-47 \%$ of control within $8-12 \mathrm{hr}$ in eight hypothyroid patients. This fall also was followed by significant $\mathrm{TSH}$ rises above control values before they returned to the pretreatment levels. Mineralocorticoid administration was not followed by any changes in plasma TSH concentrations in three subjects.

TSH responses to steroid were also studied in rats. In hypothyroid rats given dexamethasone intravenously, plasma TSH fell to $63 \%$ of control in 30-90 min and then returned to normal or above in 3-4 hr. Dexamethasone also reduced plasma TSH concentrations in normal rats but no rebound was observed in these animals. Dexamethasone did not block the increase in plasma TSH produced by thyrotropin releasing factor (TRF) administration in vivo. Neither basal nor TRF-mediated TSH release from hemipituitaries in vitro was reduced by dexamethasone or corticosterone. These studies indicate that glucocorticoids reduce TSH secretion and suggest that this effect occurs at a suprahypophyseal level.

\section{INTRODUCTION}

Considerable evidence indicates that both natural and synthetic glucocorticoid hormones inhibit various param-

Received for publication 19 May 1969 and in revised form 7 July 1969. eters of thyroid function in both man and laboratory animals. Thyroidal iodide clearance rates, thyroid 24 and $48 \mathrm{hr}$ iodide uptake values, thyroid secretion rates, plasma protein-bound iodide (PBI) concentrations, and various other less direct indices of thyroid function have all been shown to fall after administration of these agents in large doses (1-4). The magnitude of these changes is frequently considerable and, in some patients, iodide uptake or clearance measurements and plasma thyroid hormone concentrations fall to values ordinarily found only in hypothyroid patients. Some of these effects have been reported to occur within 1 day after glucocorticoid administration is initiated (5) and they generally persist as long as steroids are administered. However, they are entirely reversible. Reductions in PBI do not occur when glucocorticoids are given to hypothyroid patients receiving thyroid replacement therapy (6). Changes in peripheral thyroxine metabolism and in the pattern of thyroxine binding to plasma proteins during glucocorticoid treatment have also been described (6-8). The mechanism of the thyroid suppression produced by glucocorticoids is unknown though most of the published data are consistent with the hypothesis that glucocorticoids impair the secretion of thyrotropin (TSH) from the anterior pituitary gland. This report provides direct evidence that $\mathrm{TSH}$ secretion is altered during and after glucocorticoid administration and that the effect of these agents is exerted at a suprahypophyseal level, rather than on the pituitary gland itself.

\section{METHODS}

Studies in human subjects. All studies were carried out in hospitalized subjects. The patients' diagnoses were established by appropriate clinical and laboratory observations including measurement of plasma PBI and thyroxine (9) and thyroidal radioiodide uptake at 6 and $24 \mathrm{hr}$. All the clinically hypothyroid patients studied had elevated plasma TSH concentrations, thus confirming the diagnosis of primary hypothyroidism. Glucocorticoids were given according to three regimens. The first consisted of oral administration of 2 or $8 \mathrm{mg}$ dexamethasone in divided doses for 1-2 days. The second involved single oral doses of dexamethasone or cortisol. Lastly, two patients received cortisol intravenously.

2096 The Journal of Clinical Investigation Volume 481969 
TABLE I

TSH Values during and after Dexamethasone in Hypothyroid Subjects

\begin{tabular}{|c|c|c|c|c|c|c|c|c|c|c|c|c|}
\hline \multirow[b]{3}{*}{ Case } & \multirow[b]{3}{*}{ Steroid dose and duration } & \multicolumn{11}{|c|}{ TSH concentration } \\
\hline & & \multirow[b]{2}{*}{ Control } & \multicolumn{3}{|c|}{ Dexamethasone } & & \multicolumn{6}{|c|}{ Post-treatment } \\
\hline & & & 8* & 16 & 24 & & $32 *$ & 40 & 48 & 56 & 64 & 72 \\
\hline & & \multicolumn{11}{|c|}{$m \mu g / m l$} \\
\hline M. Y. & $0.5 \mathrm{mg} \mathrm{q} 6 \mathrm{~h} \times 4$ & 8.5 & 4.0 & 4.0 & 3.1 & & 3.7 & 14.6 & 18.2 & 15.5 & 10.2 & 7.6 \\
\hline M. E. & “ & 4.6 & 3.2 & 2.2 & 3.3 & & 4.6 & 10.1 & 8.8 & & & \\
\hline R. H. & “ & 15.9 & 11.0 & 15.7 & 14.2 & & 15.5 & 13.7 & 18.6 & & & \\
\hline S. M. & “ & 78.0 & 70.0 & 80.0 & 87.0 & & 82.0 & 70.0 & & & & \\
\hline R. M. & “ & 30.2 & 14.5 & 25.0 & 22.6 & & 29.6 & 38.8 & 47.0 & 29.0 & 35.7 & 36.8 \\
\hline H. K. & “ & 11.4 & & 12.8 & 9.8 & & 9.8 & 13.2 & 12.0 & 11.8 & 12.2 & \\
\hline S. C. & “ & 7.5 & 2.2 & & 1.7 & & 5.6 & 8.1 & 9.5 & 10.0 & & \\
\hline M. W. & “ & 5.1 & 2.4 & 1.4 & 2.2 & & 1.8 & 4.1 & 15.0 & 14.2 & 16.0 & 21.4 \\
\hline L. M. & $2 \mathrm{mg} \mathrm{q} 6 \mathrm{~h} \times 4$ & 11.8 & 5.4 & 3.8 & 5.6 & & 10.5 & 26.0 & 20.0 & 14.4 & 12.6 & 13.2 \\
\hline R. N. & " & 16.1 & 5.7 & 4.2 & 6.6 & & 11.8 & 20.4 & 24.0 & 16.2 & 14.2 & 14.9 \\
\hline R. M. & “ & 32.1 & 18.5 & 12.0 & 11.5 & & 17.0 & 31.8 & 37.0 & 34.2 & 32.5 & 33.5 \\
\hline \multirow[t]{2}{*}{ N. H. } & $4 \mathrm{mg} \mathrm{q} 6 \mathrm{~h} \times 4$ & 11.0 & 6.1 & 6.5 & 6.0 & & 6.9 & 8.0 & 11.6 & 10.6 & 8.2 & 10.5 \\
\hline & & & \multicolumn{7}{|c|}{ Dexamethasone } & \multicolumn{3}{|c|}{ Post-treatment } \\
\hline $\mathbf{M}$ & & & $8^{*}$ & 16 & 24 & 32 & 40 & 48 & & $56^{*}$ & 64 & 72 \\
\hline A. $\mathrm{S}$. & $0.5 \mathrm{mg} \mathrm{q} 6 \mathrm{~h} \times 8$ & 126 & 88 & 82 & 59 & 118 & 150 & 108 & & 79 & 180 & 140 \\
\hline R. J. & "1 & 12.0 & 12.0 & 11.2 & & 13.0 & & 16.0 & 0 & 13.5 & 16.5 & \\
\hline J. McD. & “ & 120 & 100 & 95 & & 82 & & 88 & & 110 & 160 & \\
\hline J. W. & “" & 36.2 & 30.5 & 20.8 & & 11.0 & & 30.0 & .0 & 26.0 & 48.5 & 35.0 \\
\hline S. A. & “" & 8.5 & 7.2 & 5.3 & & 5.3 & 4.8 & & & 12.0 & 13.5 & \\
\hline J. F. & “ & 149 & 108 & 112 & & & 109 & 125 & & 165 & & \\
\hline
\end{tabular}

* Hours after initiation of treatment.

Blood samples were collected two to four times daily before, during, and after steroid administration in the multidose studies and one to two times before single dose oral or intravenous administration and frequently thereafter for 24-72 hr. A similar schedule of sample collection was followed in a series of studies in which metyrapone (SU4885) was given in 750-mg doses every $4 \mathrm{hr}$ for 1 day. The separated plasma was frozen and all samples from an individual study were then assayed at the same time. Pretreatment values were averaged to obtain a control mean. The percentage deviation from this control mean of the plasma TSH values observed during and after the steroid administration was calculated to facilitate comparison of changes in subjects who had widely differing pretreatment plasma TSH concentrations. Statistical comparisons of the percentage means of the lowest and highest $\mathrm{TSH}$ values to the pretreatment mean were done by Student's $t$ test.

TSH was measured by a double antibody radioimmunoassay method (10) employing human TSH-125I, anti-human TSH serum, and purified human TSH (11) and the $\mathrm{Na}$ tional Institute of Medical Research Human Thyrotropin Research Standard A (NIMR-A) as immunoassay standards. Before each assay, the TSH- ${ }^{125} \mathrm{I}$ was purified by gel filtration on Sephadex G100 to remove aggregated iodinated products which accumulate during storage. In normal subjects, plasma TSH concentrations range from $<0.5$ to 3 $\mathrm{m} \mu \mathrm{g} / \mathrm{ml}(<2-12 \mu \mathrm{U}$ NIMR-A/ml) and activity is detectable in $>85 \%$ of them. For purposes of comparison in this report, undetectable $\mathrm{TSH}$ concentrations were arbitrarily given the value of the sensitivity limit of the assay in which they were measured. Duplicate measurements of 60 plasma samples containing widely differing quantities of TSH differed by an average of $\pm 4 \%$ of their mean.

Rat TSH studies. In vivo studies were carried out in pentobarbital-anesthetized 250-350 g Sprague-Dawley rats in whom an indwelling intravenous catheter had been placed.
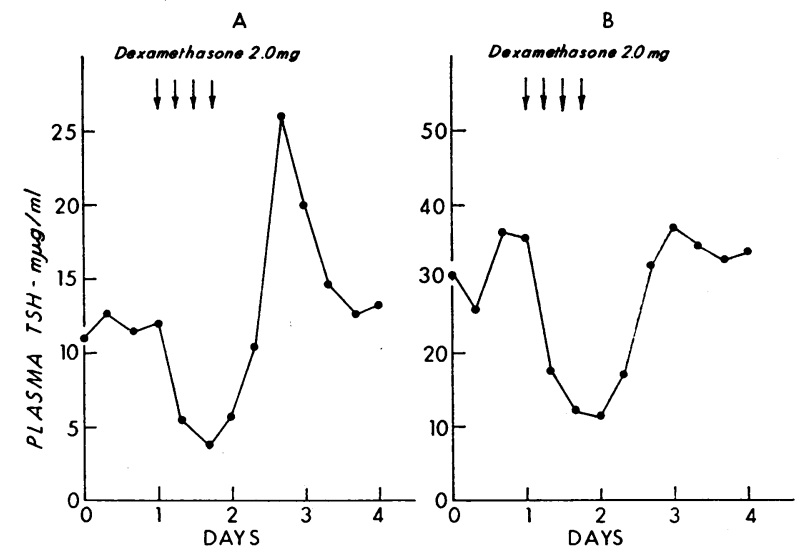

Figure 1 Plasma TSH concentrations in two hypothyroid patients before, during and after oral administration of multiple 2-mg doses of dexamethasone. 
TABLE II

Plasma TSH after Single Doses of Glucocorticoids and Mineralocorticoid in Hypothyroid Subjects

\begin{tabular}{|c|c|c|c|c|c|c|c|c|c|c|c|c|}
\hline \multirow[b]{3}{*}{ Case } & \multirow[b]{3}{*}{ Steroid* dose and route } & \multicolumn{11}{|c|}{ TSH concentration } \\
\hline & & \multirow[b]{2}{*}{ Control } & \multicolumn{10}{|c|}{ Time after steroid administration, $\mathrm{hr}$} \\
\hline & & & 2 & 4 & 6 & 8 & 12 & 16 & 24 & 36 & 48 & 72 \\
\hline & & & & & & \multicolumn{3}{|c|}{$m \mu g / m l$} & \multicolumn{3}{|c|}{. } & \\
\hline C. M. & $\mathrm{F}, 50 \mathrm{mg}$ po & 19.0 & & 15.0 & & 9.0 & 14.0 & 22.5 & 22.0 & 30.5 & 23.0 & \\
\hline R. M. & $\mathrm{F}, 100 \mathrm{mg}$ po & 32.0 & 25.2 & 17.8 & & 11.5 & 21.0 & & 27.5 & 47.0 & 36.5 & \\
\hline R. H. & F, $200 \mathrm{mg}$ i.v. & 19.8 & & 12.2 & & 8.4 & & 10.8 & 21.8 & 16.4 & 18.0 & \\
\hline R. T. & F, 200 mg i.v. & 25.0 & 11.8 & 7.0 & & 4.4 & 10.2 & 16.4 & 19.0 & & & \\
\hline C. P. & $\mathrm{F}, 200 \mathrm{mg}$ po & 18.2 & & 19.9 & & 10.1 & 5.9 & 15.7 & 19.8 & & & \\
\hline L. M. & $\mathrm{F}, 200 \mathrm{mg}$ po & 13.9 & 13.2 & 10.2 & & 7.4 & 5.8 & & 19.8 & 13.8 & 14.3 & \\
\hline R. M. & $\mathrm{F}, 400 \mathrm{mg}$ po & 33.0 & & 21.5 & & 10.0 & & 11.2 & 34.0 & 60.0 & 37.0 & 33.2 \\
\hline W. L. & $\mathrm{D}, 2 \mathrm{mg}$ po & 26.8 & & & 20.5 & & 10.5 & & 25.5 & 40.0 & 35.0 & \\
\hline J. L. & $\mathrm{D}, 8 \mathrm{mg}$ po & 29.2 & 24.2 & & 15.1 & 9.8 & 9.5 & & 16.4 & 37.8 & 29.2 & \\
\hline R. M. & fl. $-F, 0.2 \mathrm{mg}$ po & 17.0 & & 17.0 & & 17.0 & 21.5 & & 17.0 & 19.5 & 16.0 & \\
\hline C. P. & fl.-F, $0.2 \mathrm{mg}$ po & 4.3 & & 4.0 & & 4.0 & 5.0 & 4.2 & 6.0 & 5.8 & & \\
\hline R. H. & fl. $-F, 0.5 \mathrm{mg}$ po & 16.0 & & 15.5 & & 17.5 & 18.0 & & 19.0 & 15.0 & 18.0 & \\
\hline
\end{tabular}

${ }^{*} \mathrm{~F}=$ cortisol, $\mathrm{d}=$ dexamethasone, $\mathrm{fl}-\mathrm{F}=9 \alpha$-fluorohydrocortisone.

Dexamethasone was given intravenously alone as well as simultaneously with a partially purified preparation of thyrotropin releasing factor (TRF A, kindly supplied by Dr. W. White, Abbott Laboratories) and multiple $1 \mathrm{ml}$ blood samples collected. Blood removed was replaced by isotonic $\mathrm{NaCl}$. Hypothyroidism was induced by the addition of $0.05 \%$ propylthiouracil to the drinking water for $2-4 \mathrm{wk}$.

TSH secretion was also studied in vitro by measuring TSH release from single rat hemipituitaries incubated in 1.0 $\mathrm{ml}$ medium TC- 199 with $10 \%$ calf serum at $37^{\circ} \mathrm{C}$ in an atmosphere of $95 \% \quad \mathrm{O}_{2}-5 \% \quad \mathrm{CO}_{2}$ (12). After a 3-4 hr preincubation period, necessary to allow $\mathrm{TSH}$ release to fall to a constant rate, the medium was changed and two successive $1 \mathrm{hr}$ incubation periods carried out. The 1st hour served as a control period. During the 2 nd hour, TRF was added to each flask and dexamethasone or corticosterone in varying doses to the flasks containing one of each hemipituitary pair. Each experimental group had four hemipituitaries. Results of medium TSH assays were expressed as the percentage of that found in the control medium from the same hemipituitary. In one experiment, half of the rats were given $100 \mu \mathrm{g}$ dexamethasone intravenously $20 \mathrm{~min}$ before hypophysectomy and the steroid was included in all subsequent incubation media containing these hemipituitaries.

Rat plasma and medium TSH was measured by a specific double antibody immunoassay which employs mouse thyrotropic tumor TSH- ${ }^{125} \mathrm{I}$, anti-bovine TSH serum, and USP bovine TSH as immunoassay standard (13). This system can detect as little as $5 \mu \mathrm{U} \mathrm{TSH} / \mathrm{ml}$ plasma and its reproducibility is similar to that of the human TSH assay.

\section{RESULTS}

\section{Studies in hypothyroid patients}

During the control period, plasma TSH concentrations were quite constant in each of the 17 patients. The average difference of the pretreatment values from their mean was $\pm 10.7 \%$ and, in any individual study, no result differed by more than $\pm 27 \%$ of the mean for that patient. The data from all the patients who received multiple doses of dexamethasone are shown in Table I and two individual responses are shown in Fig. 1. In 15 of these 17 hypothyroid patients (two studies being done in one pateint), a fall in plasma TSH occurred after the first dose of steroid. It then frequently fell lower as steroid administration was continued, but in eight patients plasma TSH returned toward baseline

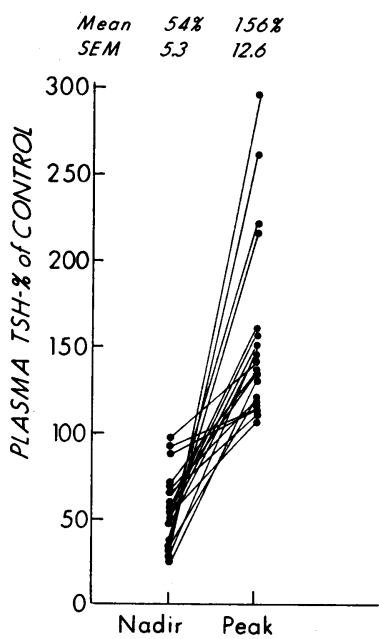

FIgURE 2 Lowest plasma TSH concentrations observed during multiple dose dexamethasone treatment and highest $\mathrm{TSH}$ value found after steroid in the 17 hypothyroid patients (18 studies). Data from individual patients are connected. TSH values are expressed as percentage of the control value. 
TABLE III

Plasma TS.H Concentrations during and after Dexamethasone in Normal Subjects

\begin{tabular}{|c|c|c|c|c|c|c|c|c|c|c|c|}
\hline \multirow[b]{3}{*}{ Case } & \multirow[b]{3}{*}{ Steroid dose and duration } & \multicolumn{10}{|c|}{ TSH concentration } \\
\hline & & \multirow[b]{2}{*}{ Control } & \multicolumn{3}{|c|}{ Dexamethasone } & \multicolumn{6}{|c|}{ Post-treatment } \\
\hline & & & $8^{*}$ & $\mathrm{hr}^{16}$ & 24 & $32^{*}$ & 40 & 48 & 56 & 64 & 72 \\
\hline & & \multicolumn{10}{|c|}{$m \mu g / m l$} \\
\hline C. B. & $0.5 \mathrm{mg} \mathrm{q} 6 \mathrm{~h} \times 4$ & 1.0 & 0.7 & 0.8 & 0.8 & 0.8 & 1.1 & 0.8 & 0.6 & 1.2 & 1.0 \\
\hline M. B. & “ & 0.7 & 0.6 & 0.7 & 0.6 & 0.6 & 0.8 & 0.6 & & & \\
\hline B. T. & “ & 0.9 & 0.8 & 0.8 & 1.0 & 1.4 & 1.5 & & & & \\
\hline C. M. & “ & 0.6 & $<0.5$ & $<0.5$ & & 0.7 & & & & & \\
\hline D. M. & “ & 1.0 & $<0.6$ & 0.6 & & 0.7 & 1.6 & 1.2 & 1.3 & 1.0 & 0.8 \\
\hline C. McC. & “ & 0.0 & 0.5 & 0.6 & 0.6 & 0.6 & 0.8 & 0.8 & 0.9 & 1.4 & 1.1 \\
\hline R. M. & “ & 0.5 & $<0.5$ & $<0.5$ & 0.5 & 0.5 & 0.5 & 0.5 & 0.5 & 0.5 & 0.5 \\
\hline L. R. & $0.5 \mathrm{mg} \mathrm{q} 6 \mathrm{~h} \times 8$ & 0.8 & 0.7 & 0.7 & 0.6 & 0.7 & 1.1 & 1.2 & 0.8 & 0.8 & \\
\hline C. W. & “ & 0.6 & 0.6 & 0.7 & 0.6 & 0.9 & 0.6 & 0.6 & 0.8 & & \\
\hline W. C. & $2 \mathrm{mg} \mathrm{q} 6 \mathrm{~h} \times 4$ & 0.6 & 0.6 & 0.6 & 1.1 & 0.9 & 0.9 & 1.4 & 1.0 & & \\
\hline C. McL. & “" & 0.9 & 0.8 & 0.7 & 0.6 & 0.8 & 0.8 & 1.7 & 1.7 & 1.5 & 1.3 \\
\hline H. S. & “ & 0.8 & 0.8 & 0.6 & 0.6 & 0.6 & 0.6 & 1.0 & 0.8 & 0.8 & \\
\hline P. M. & $4 \mathrm{mg} 16 \mathrm{~h} \times 4$ & 0.6 & 0.6 & 0.6 & 0.6 & 0.6 & 0.6 & 1.2 & 1.0 & 1.0 & 1.0 \\
\hline P. S. & “" & 0.8 & 0.6 & 0.6 & 0.6 & 0.6 & 0.6 & 0.8 & & & \\
\hline J. D. & “ & 0.8 & 1.0 & 0.7 & & 0.7 & 0.8 & 1.5 & 1.4 & 0.8 & \\
\hline
\end{tabular}

* Hours after initiation of treatment.

values while steroid was still being given. Considering the group as a whole (Fig. 2), the lowest plasma TSH concentration found ranged from 23 to $96 \%$ of control (mean $54 \%$ ). This difference is statistically significant $(P<0.01)$. TSH reductions to $50 \%$ of control or less occurred in nine patients. Since neither the fall in TSH during treatment nor the rise after it (see below) appeared to depend on the dose or duration of dexamethasone treatment, all results have been considered together in this analysis.

In 14 of the studies, after steroid administration, plasma TSH concentrations rose transiently above control levels. A striking example of this is shown in Fig. $1 \mathrm{~A}$, whereas its absence is apparent in the data shown in Fig $1 \mathrm{~B}$. The highest $\mathrm{TSH}$ value was observed within $48 \mathrm{hr}$ after steroids were discontinued and usually it occurred within $36 \mathrm{hr}$ after the last dose. Rises to values greater than $150 \%$ of control were found in six patients. The peak plasma TSH for the individual patients ranged from 106 to $294 \%$ of control, the mean being $156 \%$ of it (Fig. 2). This value is also significantly different from control $(P<0.01)$. It is apparent from inspection of Table I and Fig. 2 that, in an individual patient, there is some correlation between the degree of fall in plasma TSH occurring during the treatment and the height of the subsequent poststeroid TSH rise. A marked rise was not observed in any patient in whom a considerable earlier fall during steroid administration had not occurred; in each of the four patients in whom rises to values greater than $200 \%$ of control occurred, TSH had fallen to less than $50 \%$ of control during dexamethasone administration. One patient was given both 2 and 8 $\mathrm{mg}$ of dexamethasone. While receiving the smaller dose, her plasma TSH fell to $48 \%$ of control and then increased to $156 \%$. During the larger dose administration period, plasma TSH fell to $36 \%$ of control, but the post-treatment rise was to only $116 \%$ of control.

In eight patients (nine studies), plasma TSH was measured frequently before and after administration of

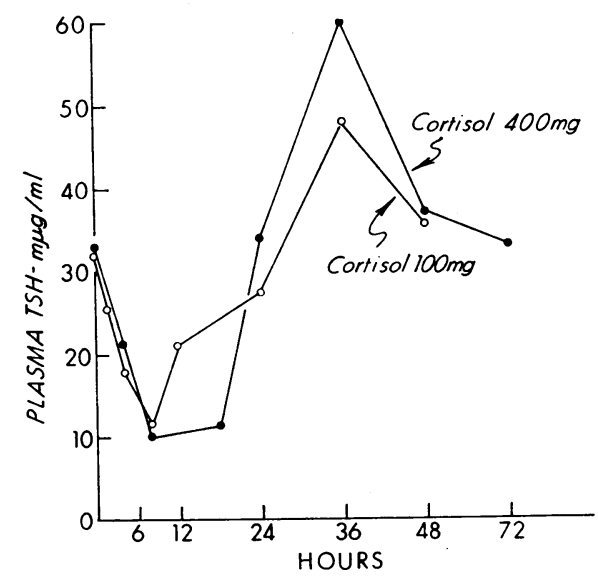

FIgURE 3 Plasma TSH concentrations following oral administration of different doses of cortisol to a hypothyroid patient on two separate occasions.

Glucocorticoids and TSH Secretion 
single oral doses of dexamethasone or cortisol given orally or intravenously (Table II). As expected from the results presented in Table $I$, in all studies a fall in plasma TSH occurred. This fall was also unrelated to the dose, type, or route of administration of steroid employed. Fig. 3 shows the results obtained with two different doses of cortisol in one patient. The TSH reduction was often apparent within 2-4 hr and was usually maximal 8 or $12 \mathrm{hr}$ after steroid administration. The mean maximal TSH fall in this entire group was to $35 \%$ of control values and ranged from 18 to $47 \%$ (Fig. 4) and was highly statistically significant $(\mathrm{P}<$ $0.005)$. Thereafter, plasma TSH concentrations returned to control values (three patients) or above (five patients), the highest observed values in this group of studies ranging from 76 to $182 \%$ of control (mean $134 \%$ ). This peak occurred 24 or $36 \mathrm{hr}$ after steroid administration. The lack of an appreciable "rebound" in several patients may have been due to insufficient study duration. Thus, the responses to single dose steroid administration were similar to those observed in the more numerous multple dose studies. Three studies were carried out after mineralcorticoid (9 $\alpha$-fluorohydrocortisone) administration (Table II). No changes in plasma TSH were observed.

\section{Studies in normal subjects}

Dexamethasone was also given orally in multiple doses to 15 normal subjects (Table III). Plasma TSH concentrations were initially detectable in each of these subjects and quite constant in each during the pretreatment sampling period. The average difference from the mean of the pretreatment values was $\pm 10.1 \%$ and no value differed by more than $\pm 25 \%$ of the mean in any subject. The pattern of response was similar to that observed in the hypothyroid patients, though the magni-

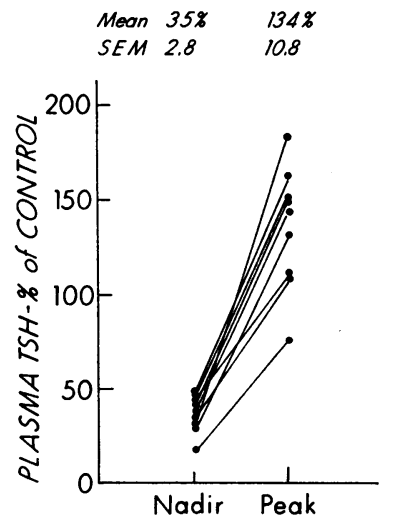

FIGURE 4 Lowest and highest plasma TSH concentrations, expressed as percentage of the control value, in each of the nine studies in hypothyroid patients after single doses of cortisol or dexamethasone.
TABLE IV

Effect of Glucocorticoids on TRF-Mediated TSH Release In Vitro

\begin{tabular}{|c|c|c|}
\hline Experimental conditions & Medium TSH* & Significance \\
\hline $\begin{array}{l}\text { 1. TRF, } 5 \mu \mathrm{g} / \mathrm{ml} \\
\text { TRF + dexamethasone, } \\
0.004 \mu \mathrm{g} / \mathrm{ml}\end{array}$ & $\begin{array}{c}\text { \% of control } \pm 1 \text { SEM } \\
412 \pm 65 \\
384 \pm 34\end{array}$ & $P>0.05$ \\
\hline $\begin{array}{l}\text { 2. TRF } 5 \mu \mathrm{g} / \mathrm{ml} \\
\text { TRF + dexamethasone, } \\
0.4 \mu \mathrm{g} / \mathrm{ml}\end{array}$ & $\begin{array}{l}437 \pm 48 \\
381 \pm 35\end{array}$ & $P>0.05$ \\
\hline $\begin{array}{l}\text { 3. TRF, } 2 \mu \mathrm{g} / \mathrm{ml} \\
\text { TRF + dexamethasone, } \\
4.0 \mu \mathrm{g} / \mathrm{ml}\end{array}$ & $\begin{array}{l}666 \pm 89 \\
679 \pm 76\end{array}$ & $P>0.05$ \\
\hline $\begin{array}{l}\text { 4. TRF, } 2 \mu \mathrm{g} / \mathrm{ml} \\
\text { TRF + corticosterone, } \\
35 \mu \mathrm{g} / \mathrm{ml}\end{array}$ & $\begin{array}{l}265 \pm 30 \\
314 \pm 45\end{array}$ & $P>0.05$ \\
\hline $\begin{array}{l}\text { 5. TRF, } 5 \mu \mathrm{g} / \mathrm{ml} \\
\text { TRF }+ \text { dexamethasone, } \\
100 \mu \mathrm{g} \text { i.v. in vivo, } \\
0.4 \mu \mathrm{g} / \mathrm{ml} \text { in vitro } \ddagger\end{array}$ & $546 \pm 80$ & $P>0.05$ \\
\hline
\end{tabular}

* Mean of mediun TSH, as percent of preceding control hour value, in four to five flasks, each flask containing one hemipituitary.

¥In vivo dexamethasone given $20 \mathrm{~min}$ before hypophysectomy.

tude of the changes in TSH concentration were very much smaller. The mean of the lowest TSH values observed during steroid administration was $82 \%$ of control (range 50-100\%) (Fig. 5). It should be pointed out, however, that many of the control values were sufficiently close to the sensitivity threshold of the assay so that greater reductions in plasma TSH that could not

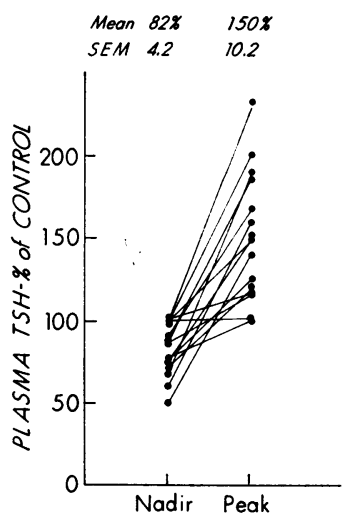

Figure 5 Nadir plasma TSH values, expressed as percentage of the control value, observed during multiple dose dexamethasone treatment and peak TSH values found after steroid in each of the 15 normal subjects. 
be detected may well have occurred. Within the $48 \mathrm{hr}$ period after treatment, plasma TSH concentrations increased to greater than $150 \%$ of pretreatment values in seven subjects and to $200 \%$ or greater in two of them. The mean of the highest TSH values was $150 \%$ of control (range 100-233\%) (Fig. 5). The means of both the lowest and the highest values observed differed significantly from the pretreatment values $(P<0.05$ and $P<0.01$ ).

Plasma thyroxine or PBI concentrations were measured in all of the blood samples from many of the hypothyroid and normal subjects. No significant changes were found.

\section{Studies with metyrapone}

The effect of metyrapone on TSH secretion was examined in 6 normal and 15 hypothyroid subjects. In the normal subjects, plasma TSH concentrations did not vary by more than $\pm 20 \%$ of control at any time during or after administration of this agent. Similar findings were observed in nine of the hypothyroid subjects. However, in six of the latter group, rises in plasma TSH concentrations to values greater than $140 \%$ of control occurred during the period of administration. All subjects had normal urinary 17 -hydroxycorticosteroid responses to the metyrapone (14).

\section{Studies in rats}

In vivo studies. The administration of $100 \mu \mathrm{g}$ dexamethasone intravenously to anesthetized normal rats was followed by a significant fall in plasma TSH (Fig. 6). No change occurred in animals not given steroid. The $\mathrm{TSH}$ reduction was apparent within $30 \mathrm{~min}$ and was maximal $1 \mathrm{hr}$ after steroid administration, the mean TSH value being $48 \%$ of control at that time. No sub-

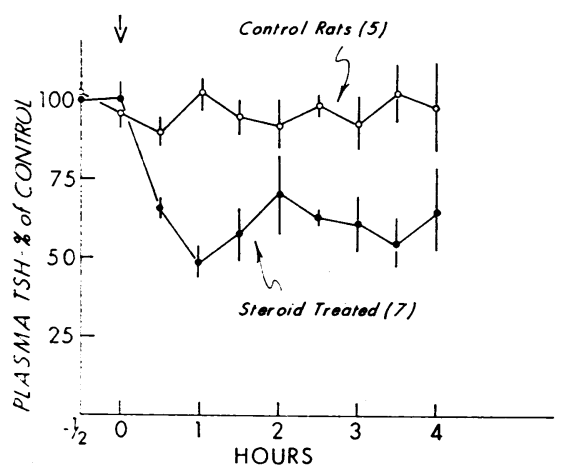

FIGURE 6 Mean plasma TSH concentrations, expressed as percentage of the control values, in normal rats after the intravenous administration of dexamethasone (closed circles) and saline (open circles). Vertical bars indicate \pm 1 SEM. Postinjection values in the dexamethasone-treated animals differed significantly $(P<0.01)$ from those in the salinetreated animals at all times except at 2 and $4 \mathrm{hr}$.

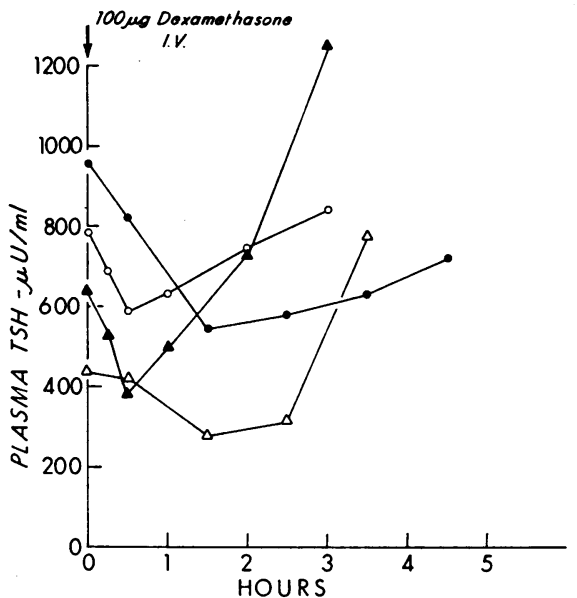

FIGURE 7 Changes in plasma TSH concentrations in four hypothyroid rats after the intravenous administration of $100 \mu \mathrm{g}$ dexamethasone.

sequent values exceeded $70 \%$ of control. Return to or above control levels may have been masked by removal of considerable quantities of blood, the effects of anesthesia, or insufficient study duration. A similar fall in $\mathrm{TSH}$ was observed in hypothyroid rats and in three of the four animals TSH concentrations returned to or above control values (Fig. 7 ). It has previously been shown that plasma TSH levels remained quite constant when anesthetized hypothyroid rats were given saline intravenously (13).

In other animals the ability of dexamethasone to block the action of TRF in vivo was examined. After anesthesia and catheter implantation, $100 \mu \mathrm{g}$ dexamethasone and $25 \mu \mathrm{g}$ TRF were given intravenously. Controls received only TRF. The results are shown in Fig. 8. In both groups of animals, plasma TSH concentrations increased significantly $(P<0.01)$ promptly after TRF injection. Neither the magnitude nor the duration of the TRF-induced plasma TSH increase was modified by the administration of dexamethasone. Insufficient TRF was available to test the possibility that the effect of larger doses might be blunted by glucocorticoids.

In vitro studies. Additional studies to examine the effect of steroids on TRF-mediated TSH secretion were carried out in vitro. The results are shown in Table IV. When compared with the preceeding control hour, addition of 2 or $5 \mu \mathrm{g}$ TRF to the medium resulted in a $265-666 \%$ increase in medium TSH concentration in these experiments. Incubation of pituitaries with either dexamethasone or corticosterone did not result in inhibition of TRF stimulation in any of the experiments. Furthermore, TRF stimulation was not reduced by dexamethasone treatment before hypophysectomy and exposure of the hemipituitaries to the steroid throughout the preincubation and control periods. 


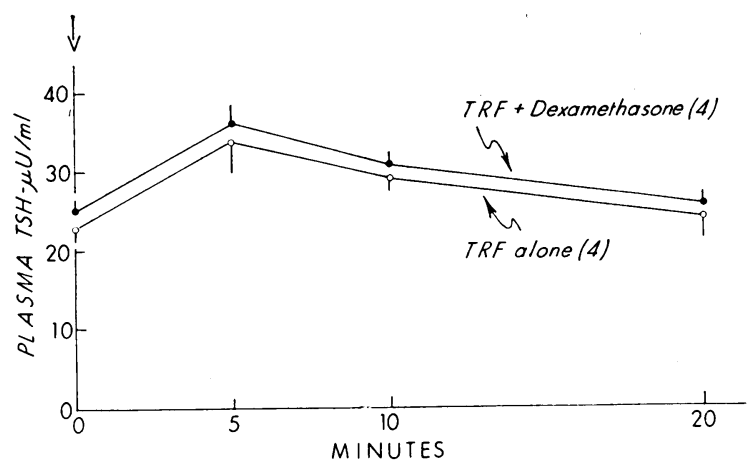

FIGURE 8 Mean plasma TSH concentrations in rats after TRF and dexamethasone (closed circles) and TRF alone (open circles). Four rats in each group. Vertical bars indicate \pm 1 sEM.

Hemipituitaries were also incubated with dexamethasone starting immediately after their removal and hourly changes in medium were made for $4 \mathrm{hr}$. The usual pattern of fall of medium TSH concentrations to stable levels of approximately $10 \%$ of the 1 st hour concentration by the 3 rd and 4th hours was observed in media from hemipituitaries incubated both with and without steroid. Thus, basal TSH release in vitro was also unaffected by steroid.

\section{DISCUSSION}

The studies herein described clearly demonstrate that glucocorticoid administration results in reduction in plasma TSH concentrations in both hypothyroid and normal human subjects. Thus, these data provide direct support for the hypothesis of Ingbar and Freinkel concerning glucocorticoid inhibition of thyroid function (3). The TSH suppressive effect of glucocorticoids occurs within hours after their administration and the tendency for plasma TSH concentrations to return toward the pretreatment level during steroid treatment in some subjects suggests the potentiality for escape from this process. The responses to prolonged steroid administration have not been examined in detail, but in one hypothyroid patient given $40 \mathrm{mg}$ prednisone daily for $2 \mathrm{wk}$ the plasma TSH fell from 23 to $3.5 \mathrm{~m} \mu \mathrm{g} / \mathrm{ml}$. The fall in $\mathrm{TSH}$ in normal subjects was of lesser magnitude and the percentage changes smaller than those observed in the hypothyroid patients. However, control plasma TSH concentrations were often so near the sensitivity threshold of the assay in the normal subjects that greater falls in plasma TSH that could not be appreciated may have occurred. The doses required to produce these changes were not large and, at least within the range used in this study, larger doses of steroid did not result in greater TSH changes. Moreover, similar patterns of change followed administration of both single and mul- tiple doses of dexamethasone. The results of the in vivo studies in rats confirm this suppressive action of glucocorticoids on TSH secretion. The changes in plasma TSH concentrations observed during the metyrapone studies, while observed only in hypothyroid patients and than inconstantly, indicate that glucocorticoid deficiency can affect TSH secretion in a manner opposite to that of glucocorticoid excess.

What can be said concerning the mechanism of this action of corticosteroids? It can be produced by both natural and synthetic compounds having glucocorticoid administration. The studies in rats indicate that glucocorticoids do not reduce the release of TSH in vitro nor do they impair the ability of the pituitary, either in vivo or in vitro, to respond to TRF. Thus, it would appear that their action is exerted at a suprahypophyseal level and leads, whether directly or secondarily, to inhibition of the secretion of TRF. One can only speculate about possible loci within the nervous system, since steroid-sensitive neurons have been identified in many areas of it (15). Alternatively, the action of glucocorticoids might be to accelerate the degradation of TSH by peripheral tissue or to increase the TSH distribution space. These possibilities have not been investigated but seem unlikely. Accelerated degradation or altered distribution of TSH might explain the fall in plasma TSH concentrations observed; it is difficult to see how such a mechanism could result in the post-treatment rebound. Glucocorticoids have been shown to reduce the binding capacity of plasma thyroxine binding globulin (TBG) and increase that of thyroxine binding prealbumin (TBPA) (8). Since no changes in net thyroxine binding were reported in that study and the changes described took at least a week to develop, glucocorticoid effects on thyroxine transport cannot account for the TSH changes reported herein.

$\mathrm{TSH}$ rebound was observed in a high proportion of both hypothyroid and normal human subjects and hypothyroid rats. During glucocorticoid treatment when TRF secretion is presumably impaired, it could accumulate intracellularly in the appropriate hypothalamic centers. Subsequently, this accumulated TRF might be rapidly released and therefore briefly stimulate TSH secretion through its known pituitary action. Whatever the mechanism of the TSH rebound, it represents the first demonstration of increased TSH secretion in the adult not resulting from either reduced circulating thyroid hormone concentrations or TRF administration (16). It also suggests that alterations in TSH secretion are not determined entirely by changing plasma thyroid hormone levels interacting with unvarying TRF concentrations at the level of the pituitary thyrotroph, but that alterations in TRF secretion can also participate in regulating TSH secretion. 
It is possible that, by alteration of dose, duration, or type of steroid, this poststeroid rebound in plasma TSH concentrations can be regularly elicited and its degree magnified in normal subjects. It might then prove useful in the assessment of TSH reserve capacity in man. To the present, only two procedures have been shown to increase TSH secretion in normal human subjects. One is by the administration of antithyroid drugs, but several weeks of such therapy are often insufficient to produce elevated plasma TSH concentrations (10). Thus, this is not a practical clinical test. The second is by the administration of TRF. This has been shown to elevate plasma TSH rapidly in hypothyroid human subjects (16) and no doubt would do so in normal subjects, but is not likely to be available for general use for some time.

The secretion of several anterior pituitary hormones in man has been shown previously to be altered by glucocorticoids. That these agents regulate ACTH secretion is well known and effects on MSH secretion have also been described (17). Impairment of the increase in plasma growth hormone $(\mathrm{GH})$ which follows insulin-induced hypoglycemia during glucocorticoid administration has been reported during some but not all experimental conditions (18-21), whereas the rise in plasma GH provoked by arginine infusion is not impaired by short-term steroid treatment (20). While the glucocorticoid doses used were supraphysiologic, it has herein been shown that TSH should be added to the number of anterior pituitary hormones whose secretion is reduced by these agents and it is the first for which a rise above control values has been observed after treatment.

\section{ACKNOWLEDGMENTS}

We wish to acknowledge the assistance of Mrs. Rebecca Lehmann, Mrs. Judith Roy, Miss Jayne Martin, and Miss Mary Jane Franklin.

This work was supported in part by Research Grant AM 08630 and Training Grant AM 05027 from the U. S. Public Health Service. Clinical studies were carried out on the Clinical Research Centers of the Washington University School of Medicine and the Northwestern University School of Medicine, supported by U. S. Public Health Service Grants FR-36 and FR-48 respectively.

\section{REFERENCES}

1. Albert, A. 1952. The thyroid gland. Annu. Rev. Physiol. $14: 481$.

2. Money, W. L. 1955. The interrelation of the thyroid and the adrenals. Brookhaven Symp. Biol. 7: 137.

3. Ingbar, S. H., and N. Freinkel. 1956. ACTH, cortisone and the metabolism of iodine. Metabolism. 5: 652.
4. Money, W. L. 1962. The effect of steroids and stress on thyroid function. In The Thyroid Gland. S. C. Werner, editor. Harper \& Row, Publishers, New York. 2nd edition. 83.

5. Fredrickson, D. S., P. H. Forsham, and G. W. Thorn. 1952. The effect of massive cortisone therapy on measurements of thyroid function. J. Clin. Endocrinol. Metab. 12: 541 .

6. Ingbar, S. H., and N. Freinkel. 1955. The influence of $\mathrm{ACTH}$, cortisone and hydrocortisone on the distribution and peripheral metabolism of thyroxine. J. Clin. Invest. 34: 1375 .

7. Kumar, R. S., B. U. Musa, W. J. Appleton, and J. T. Dowling. 1968. Effect of prednisone on thyroxine distribution. J. Clin. Endocrinol. Metab. 28: 1335.

8. Oppenheimer, J. H., and S. C. Werner. 1966. Effect of prednisone on thyroxine-binding proteins. J. Clin. Endocrinol. Metab. 26: 715.

9. Murphy, B. P. 1965. The determination of thyroxine by competitive protein-binding analysis employing an anionexchange resin and radiothyroxine. J. Lab. Clin. Med. 66: 161.

10. Odell, W. D., J. F. Wilber, and R. D. Utiger. 1967. Studies of thyrotropin physiology by means of radioimmunoassay. Recent Progr. Hormone Res. 23: 47.

11. Condliffe, P. G. 1963. Purification of human thyrotropin. Endocrinology. 72: 893.

12. Wilber, J. F., and R. D. Utiger. 1968. In vitro studies on mechanism of action of thyrotropin releasing factor. Proc. Soc. Exp. Biol. Med. 127: 488.

13. Wilber, J. F., and R. D. Utiger. 1967. Immunoassay studies of thyrotropin in rat pituitary glands and serum. Endocrinology. 81: 145.

14. Liddle, G. W., H. L. Estep, J. W. Kendall, Jr., W. C. Williams, Jr., and A. W. Townes. 1959. Clinical application of a new test of pituitary reserve. J. Clin. Endocrinol. Metab. 19: 875 .

15. Yates, F. E. 1967. Physiological control of adrenal cortical hormone secretion. In The Adrenal Cortex. A. B. Eisenstein, editor. Little, Brown \& Co., Inc., Boston. 133.

16. Bowers, C. Y., A. V. Schally, W. D. Hawley, C. Gual, and A. Parlow. 1968. Effect of thyrotropin-releasing factor in man. J. Clin. Endocrinol. Metab. 28: 978.

17. Abe, K., W. E. Nicholson, G. W. Liddle, D. P. Island, and D. N. Orth. 1967. Radioimmunoassay of $\beta$-MSH in human plasma and tissues. J. Clin. Invest. 46: 1609.

18. Frantz, A. G., and M. T. Rabkin. 1964. Human growth hormone, clinical measurement, response to hypoglycemia, and suppression by corticosteroids. N. Engl. J. Med. 271: 1375 .

19. Hartog, M., M. A. Gaafar, and R. Fraser. 1964. Effect of corticosteroids on serum growth hormone. Lancet. 2: 376.

20. Nakagawa, K., Y. Horiuchi, and K. Mashimo. 1969. Responses of plasma growth hormone and corticosteroids to insulin and arginine with or without prior administration of dexamethasone. J. Clin. Endocrinol. Metab. 29: 35.

21. Morris, H. G., J. R. Jorgensen, and S. A. Jenkins. 1968 Plasma growth hormone concentration in corticosteroidtreated children. J. Clin. Invest. 47: 427. 